the European-Mediterranean region. The participants discussed proxy records with emphasis on their climatic interpretation and the suitability for their integration into the regional reconstruction. Particular issues that were addressed included the handling of differently resolved proxies, target variables, seasonality, preservation of low- and high-frequency variability, replication, "expert knowledge" and calibration/verification. An extended discussion took place on how proxy data should be most effectively collected. It was agreed that the community should collect only published data (using both raw and quantified analyses) from each of the different archives, with a full estimate of the uncertainties included. Importantly, objective criteria for the final selection of records must be developed prior to the generation of final statistically based reconstructions (in consultation with other regional $2 \mathrm{k}$ groups; criteria having been presented by two representatives of the Arctic2k group). Qualitative data will also be utilized to cross-check against the climate variability reconstructed from higher resolution records. As a starting point, the group was encouraged to develop a EuroMed2k metadatabase on the project's website, to develop an inventory of the records that are currently available and/or being actively developed in the Euro-Med region. Discussions also focused on different statistical methods used in paleoclimatology that can integrate multiproxy data.

A better understanding of the strengths and weaknesses of established and new reconstruction methods and the behavior of different climate proxies was considered essential to reduce uncertainties and biases. A variety of available methods were presented including Bayesian hierarchical modeling and Neural Networks using pseudo-proxy data. These methods provide an estimate of the full covariance structure of the temperature and hydrological reconstructions, but need to be tested first using real proxy data from the Europe-Mediterranean region. A presentation provided new millennial-length coupled climate model results and ways to compare continental-scale multiproxy climate reconstructions with coupled paleoclimate model output.

The group agreed to write a peer reviewed paper including a comprehensive assessment of proxy data availability from the European-Mediterranean area, and a critical evaluation of their strengths, weaknesses, challenges and opportunities for climate reconstructions. To involve the wider community in sharing data and participating in the initiative, specialists on different archives will be approached. First results and a promotion of the initiative will be presented in the PAGES $2 \mathrm{k}$ session at the INQUA Congress in Bern in late July 2011. In parallel, data collected and published by the EU project MILLENNIUM (www.millenniumproject.net) and the ESF project MedClivar (http://www.medclivar. eu/) will be used to test different statistical methods. Preliminary reconstruction results from the European-Mediterranean area will feed a joint " $2 \mathrm{k}$ Consortium" publication, (anticipated submission in late 2011). These results might contribute to the "regional assessment" of IPCC AR5. At a later stage, other initiatives of the group will include a data-model comparison paper using the new statistics-based reconstructions from Europe-Mediterranean covering the past 2 ka with new paleoclimate runs that will become available. The second Euro-Med2k workshop will be held in early 2012.

\section{References}

Dobrovolný, P., et al., 2010: Temperature reconstruction of Central Europe derived from documentary evidence since AD 1500, Climatic Change, 101: 69-107.

Göktürk, O.M., Fleitmann, D., Badertscher, S., Cheng, H., Edwards, R.L. and Tüysüz, 0. 2011: A late-Holocene record of paleoclimate from the Kocain cave in southern Turkey, submitted.

PAGES, 2009: Science Plan and Implementation Strategy, IGBP Report No. 57, IGBP Secretariat, Stockholm.

\title{
Advancing North American climate field reconstructions: Data sources, methods development and comparisons
}

\section{$1^{\text {st }}$ PAGES North America-2k Workshop, Flagstaff, USA, 8-10 May 2011}

\author{
Henry F. Diaz' ${ }^{1}$, E.R. WAHL ${ }^{2}$ and D.S. Kaufman ${ }^{3}$ \\ 'University of Colorado, Cooperative Institute for Research in Environmental Sciences, Boulder, USA; Henry.F.Diaz@noaa.gov \\ ${ }^{2}$ National Oceanic and Atmospheric Administration/National Climatic Data Center, Boulder, USA; ${ }^{3}$ Northern Arizona University, Flagstaff, USA
}

The principal goal of the North America 2k (NAm2k) Working Group (WG) is to synthesize high-resolution, proxy-based climate reconstructions for North America for the past 2000 years. The motivation is to enhance our understanding of the patterns of natural variability of climate in North America and possible forcing mechanisms, and for comparison with high-resolution Earth System Models.

We assembled a group of climate and paleoclimate experts (see www.pages. unibe.ch/workinggroups/namerica2k for details of members) to provide an initial assessment of our capacity to carry out the task of producing a high-resolution reconstruction of key North American cli- mate variables with at least a decadal resolution. The WG considered the following: - Identification of the key paleoclimate time series available for analysis.

- Evaluation of available spatiotemporal reconstructions of the key regional climatic parameters (surface air temperature and precipitation) and reconstructions of large-scale circulation modes (e.g., AMO, PDO, ENSO).

- Validation of reconstructions through statistical methods and comparison with existing hemispheric- to globalscale multiproxy based reconstructions and climate model simulations.

The following are the major findings and action items from this workshop:
1) By far the most numerous climate proxy records for North America are tree-ring data (see e.g., Fig. 1), which are available at annual or better resolution over much of the continent. These records are sensitive to both temperature and precipitation variability. There is an extensive amount of peer-reviewed literature from more than 50 years of climatic reconstruction work that can be used for the NAm2k effort. The North America Drought Atlas (Cook et al. 2004) is currently the most extensive, high-temporal resolution paleoclimate record available for North America. It consists of gridded summer (JJA) Palmer Drought Severity Index values for the past 500-2000 years, with a trend towards 


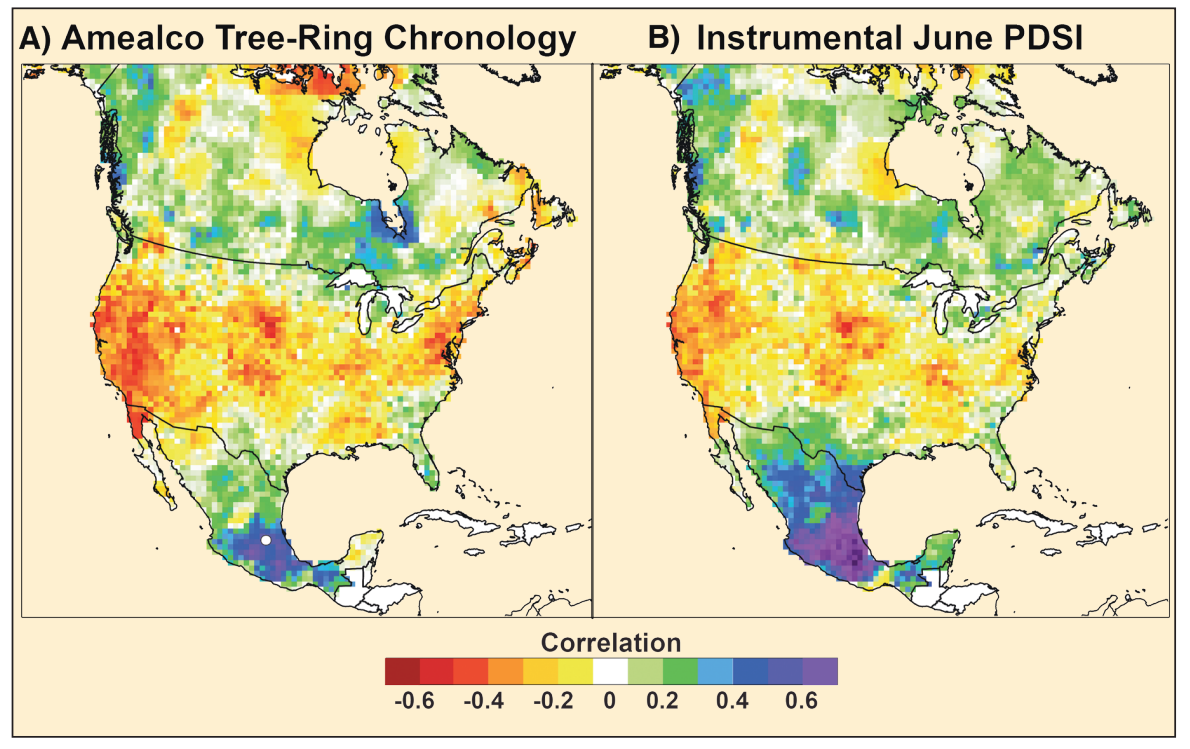

Figure 1: Central Mexico June Palmer Drought Severity Index (PDSI) correlated across North America, 1950-2003 A) Reconstructed from tree rings, B) Observed. Figure from Stahle et al. (Climate Dynamics, in review), courtesy of Dave Stahle.

longer records in western North America compared to eastern areas.

2) Other proxy records from lakes (e.g., isotopes, varves, chironomids, pollen, charcoal) are available for a number of sub-continental areas, and speleothem proxy records of precipitation are available for selected areas, such as the US Southwest. These records will generally reflect climate drivers for at least the last 2000 years, but with lower temporal reso- lution (generally) and with more limited spatial coverage than tree ring records. It was agreed that the temporal resolution of the proxy records needed for this activity would be on the order of at least 50 years, with minimum record lengths of 500 years.

3) A first step will be to develop an integrated inventory and archive of paNAm2k climate reconstruction. The goal leoclimate records for possible use in the is also to integrate the available data sets and reconstruction fields with those of the Arctic2k WG. A recommendation was made for the NOAA World Data Center for Paleoclimatology in Boulder, Colorado to become the central repository of data sets used in the NAm2k effort. The metadata could be mirrored with the PAGES $2 \mathrm{k}$ metadata archive on the PAGES website section for NAm2k.

4) A sub-working group composed of Scott Anderson, Henry Diaz, Darrell Kaufman, Brian Luckman, Dave Meko, Greg Pedersen, Dave Stahle, Valerie Trouet, Andre Viau and Gene Wahl will work toward the goal of assimilating (blending) the different input data sources and exploring mapping tools.

An analysis and synthesis workshop for the tree-ring chapter of the NAm2k Working Group is being organized, tentatively titled "North American Dendroclimatic Data: Compilation, Characterization, and Spatiotemporal Analysis" led by Valerie Trouet.

\section{References}

Cook, E.R., Woodhouse, C.A., Eakin, C.M., Meko, D.M. and Stahle, D.W. 2004: Long-term aridity changes in the western United States, Science, 306: 1015-1018.

Stahle, D.W., Burnette, D.J., Villanueva Diaz, J., Heim, R.R., Jr., Fye, F.K. Cerano Paredes, J., Acuna Soto, R. and Cleaveland, M.K., in review: Atlantic and Pacific Influences on Mesoamerican Climate Over the Past Millennium, Climate Dynamics.

\section{$2^{\text {nd }}$ International Symposium "Reconstructing climate variations in South America and the Antarctic Peninsula over the last 2000 years"}

\author{
Valdivia, Chile, 27-30 October 2010
}

\section{Duncan A. Christie ${ }^{1}$ and Andrés Rivera ${ }^{2,3}$ \\ ${ }^{1}$ Facutly of Forest Sciences and Natural Resources, Universidad Austral de Chile, Valdivia; duncanchristieb@gmail.com \\ ${ }^{2}$ Glaciology, Center for Scientific Studies (CECS), Valdivia, Chile; ${ }^{3}$ Geography Department, University of Chile, Santiago; arivera@cecs.cl}

The $2^{\text {nd }}$ International Symposium "Reconstructing Climate Variations in South America and the Antarctic Peninsula over the last 2000 years" was part of the PAGES research initiative LOTRED-SA (Long-Term climate REconstruction and Dynamics of South America). This symposium was organized by the Centro de Estudios Científi$\cos$ (CECS) and the School of Forestry and Natural Resources (Universidad Austral de Chile). Nearly 200 scientists from 15 countries (mainly from Chile, Argentina, Brazil, Colombia, Switzerland and USA) came together for oral and poster presentations, mainly related to new high-resolution paleoclimate studies in South America and the Antarctic Peninsula. Prior to the Symposium, a graduate international course "South American Climatology and Quantitative High-Resolution Climate Reconstructions in Paleoecology" took place (see PAGES news 19(1) for a report). The $2^{\text {nd }}$ International Symposium was the followup of the 2006 Malargüe-PAGES Meeting in Argentina, which had led to a special issue of Palaeogeography, Palaeoclimatology, Palaeoecology in 2009, titled Regional high-resolution multiproxy climate recon- struction for South America: state of the art and perspectives.

The goal of the 2010 meeting was to gather experts from different fields in climate dynamics, paleoclimatology (proxy data and models) and glaciology, in order to review recent discoveries, discuss new data sets, evaluate the interpretation of proxy data, and search for new calibration and quantification techniques of proxy data sets in South America and the Antarctic Peninsula. The long-term goal of this collaborative meeting was to produce a more comprehensive understanding of 